Research Article

\title{
Evaluation of the Rutting Performance of the Field Specimen Using the Hamburg Wheel-Tracking Test and Dynamic Modulus Test
}

\author{
Xiongwei Dai $(\mathbb{D}$, Yanshun Jia $(\mathbb{D}$, Shaoquan Wang $(\mathbb{D}$, and Ying Gao $i$ \\ School of Transportation, Southeast University, Nanjing 210096, China \\ Correspondence should be addressed to Ying Gao; gy@seu.edu.cn
}

Received 26 September 2019; Accepted 23 January 2020; Published 24 February 2020

Academic Editor: Hao Wang

Copyright (c) 2020 Xiongwei Dai et al. This is an open access article distributed under the Creative Commons Attribution License, which permits unrestricted use, distribution, and reproduction in any medium, provided the original work is properly cited.

\begin{abstract}
Rutting is a major distress occurring in the service life of the asphalt pavement, especially in hot weather areas. A laboratory-produced specimen is widely used for rutting performance evaluation which may not be completely represented by the field situation. The objective of this study is to evaluate the rutting performance of field specimens from the Chongqing highway by utilizing the Hamburg wheel-tracking test (HWTT) and dynamic modulus test. Different test conditions were conducted on the HWTT by investigation of the actual local weather condition. The results showed that rutting depth was different under different test conditions, and 10000 loading cycles were recommended as the maximum loading cycles. Particularly, several factors that influence the rutting depth were investigated, and the specimen height of $6 \mathrm{~cm}$ is more appropriate for the HWTT. Additionally, different test conditions were proposed as the HWTT test condition for different asphalt concrete (AC) layers in the Chongqing area. Rutting contribution of each AC layer to the pavement structure was analyzed. Moreover, the dynamic modulus at $54.4^{\circ} \mathrm{C}, 5 \mathrm{~Hz}$ and $54.4^{\circ} \mathrm{C}, 1 \mathrm{~Hz}$ could effectively represent the rutting performance of the asphalt mixture, and the dynamic modulus test is recommended for the rutting performance evaluation of the full-thickness AC layer.
\end{abstract}

\section{Introduction}

Due to the increasing traffic volume and extreme weather condition, rutting is one of the most common distress types in the asphalt pavement, which decreases the driving comfort and the pavement service life. A semirigid base and subbase are the most widely used pavement structures in China, and as a result, rutting mainly appears in the asphalt layer [1]. Considerable efforts have been made to describe the rutting performance of the asphalt mixture. Rutting relationships with other distress types of the asphalt pavement are analyzed by the association rule mining method [2]. Rahman et al. calibrated rutting, alligator cracking, longitudinal cracking, and thermal cracking prediction models of the hot-mix asphalt (HMA) overlays for Oregon conditions [3]. The Newton-Raphson iteration procedure is employed to calculate the permanent deformation [4]. A finite element (FE) model for the tire and pavement used mechanistic-empirical (M-E) approaches for qualitative prediction of the pavement rutting [5].
There are several different methods which are available to evaluate the rutting performance of the asphalt mixture. The wheel-tracking test is a very common method to evaluate the rutting performance of the asphalt mixture in China and abroad [6-8]. A three-dimensional (3D) FE model is employed to analyze the rutting performance, and it is validated by the wheel-tracking test $[9,10]$. The advanced repeated load permanent deformation (ARLPD) and conventional repeated load permanent deformation (RLPD) tests are, respectively, employed to evaluate the rutting performance on selected field cores [11]. Marshall stiffness is utilized to evaluate the resistance of the permanent deformation [12]. The Hamburg wheel-tracking test (HWTT) is utilized to assess the rutting performance of the asphalt mixture with different additives at various contents [13]. The dynamic modulus $\left(E^{*}\right)$, flow number $\left(F_{\mathrm{n}}\right)$, and flow time $\left(F_{\mathrm{t}}\right)$ tests are recommended as simple performance tests for permanent deformation of the asphalt mixture [14]. The dynamic modulus test is recommended as one of the simple performance tests for rutting evaluation of the asphalt 
mixture by NCHRP 9-19 [15]. Additionally, different studies have demonstrated that the dynamic modulus test correlates well with field rutting performance [13, 16-20]. According to literature studies $[18,21]$, both the HWTT and dynamic modulus $\left(E^{*}\right)$ tests are feasible tests for evaluating the rutting performance of the laboratory and field asphalt mixture specimens.

The rutting performance of the asphalt mixture could be easily affected by material properties, air voids, traffic, environment, aggregate gradation, and so on [11, 20, 22-25]. Actually, material properties and construction conditions of laboratory-produced specimens could not be truly represented as they exist in the field. Moreover, the rutting performance of laboratory and field specimens is not very satisfactory [26]; an important reason is that the asphalt concrete (AC) layer in the field has experienced a complex climate condition. Even, under the same air void, the laboratory specimens displayed much better performance than the field specimens [24]. Furthermore, it is more reasonable to directly evaluate the rutting performance of the field specimens. The rutting and fatigue performance is analyzed by using four field sections with stabilized/untreated base layers [27]. Rutting causes and main factors are different due to the different types of asphalt mixtures and pavement structures based on the results of field core samples [11]. The relationship among layer thickness, air content, and rutting is investigated by acquiring transversal profiles and coring pavement samples on flexible and semirigid structures [28]. Rutting prediction of semirigid pavements is calibrated, and compared to the void contents of HMA mixtures, the traffic loads and thickness of HMA are more sensitive to the rutting depth [29]. According to several research results, different temperature distribution in the pavement structure has been investigated [30-34], which indicates that different test conditions should be conducted for different depth of AC layers, and the test condition should be determined by the field weather condition.

In addition, rutting resistance performance of each AC layer in the asphalt pavement structure is different. It is observed that the permanent deformation of the middle AC layer is the highest, followed by the top and bottom AC layers based on the ARLPD test result [11]. Moreover, the top and middle AC layers are crucial to the rutting resistant performance of the high-modulus asphalt pavement [35]. $\mathrm{Hu}$ et al. [36] found that the rutting depth contribution of the top AC layer, the middle AC layer, and the bottom AC layer was about $16 \%-26 \%, 42 \%-54 \%$, and $26 \%-40 \%$, respectively. Hu et al. [37] concluded that the rutting depth contribution of the top AC layer, the middle AC layer, and the bottom AC layer was about $15 \%-50 \%, 20 \%-50 \%$, and $10 \%-50 \%$, respectively.

Based on the aforementioned studies, field specimens with various thicknesses and different test conditions are considered and the HWTT and dynamic modulus test are utilized as the test methods. The primary objective of this study is to evaluate the rutting performance of different AC layers through the HWTT and dynamic modulus test by utilizing in-service field specimens from Chongqing. The reasonable test condition of the HWTT to evaluate the rutting performance is recommended for the Chongqing area. Thus, the influence of the compaction degree, AC layer thickness, mixture type, and test condition on the rutting performance is investigated, and the rutting depth contribution of each layer is calculated under $65^{\circ} \mathrm{C}$ in the dry condition. In addition, the rutting performance of the fullthickness AC layers is analyzed by the dynamic modulus test. Furthermore, by incorporating the test results with the HWTT, the dynamic modulus threshold value of a good rutting performance is proposed for the Chongqing area.

\section{Cores and Specimen Information}

2.1. Distribution of the Field Cores. Generally, the asphalt mixture in the shoulder is regarded as the original state. However, quality control indicators were relatively weaker compared to those of the traffic lane, and the degree of compaction of the shoulder was often insufficient during the construction. Therefore, the traffic lane was more appropriate as the drilling location. Compared to that on the wheel path, there was much less traffic loading on the nonwheel path in the traffic lane, and the asphalt mixture properties in the nonwheel path were more similar to those of the original mixtures. Hence, the field cores were distributed in the nonwheel path of the traffic lane. For the accuracy of the test results, nondestruction should be guaranteed. In view of geography features of the Chongqing area, highways contain many bridges and tunnels, the material must be consistent, and the sections which were chosen for drilling cores should meet the requirements as follows:

(1) There were no obvious damages, and the rutting depth was shallow (i.e., less than $5 \mathrm{~mm}$ ).

(2) The section was flat and straight, and there was no big longitudinal slope.

(3) The section was not on bridges or in tunnels.

(4) The distance between two sections was less than $20 \mathrm{~m}$.

The position of cores was adjacent to each other, which were regarded as in one transverse section; Figure 1 shows the core distribution in a transverse section. The number of cores was $4 n-3,4 n-2,4 n-1$, and $4 n(n=1,2,3, \ldots)$, respectively. $n=1,2,3, \ldots, 10$ indicated the transverse section number was $1,2,3, \ldots, 10$. The maximum of $n$ was 10 , which represented drilling cores were conducted in 10 transverse sections, and the total number of cores was 40 . Based on the original construction data records, the 10 transverse sections were in one construction section, and the materials used in each pavement layer were consistent.

2.2. Material of the Pavement Structure. The pavement structure consisted of three asphalt layers: $4 \mathrm{~cm} \mathrm{AC-13} \mathrm{top}$ layer, $6 \mathrm{~cm} \mathrm{AC-20} \mathrm{middle} \mathrm{layer,} \mathrm{and} 6 \mathrm{~cm} \mathrm{AC-20} \mathrm{bottom}$ layer. The asphalt binder in the top AC layer was the styrenebutadiene-styrene- (SBS-) modified binder, and the asphalt binder in the other two layers was the 70\# base binder (performance graded PG 64-22); the 70\# base binder was widely used in China as the asphalt binder [38]. After 


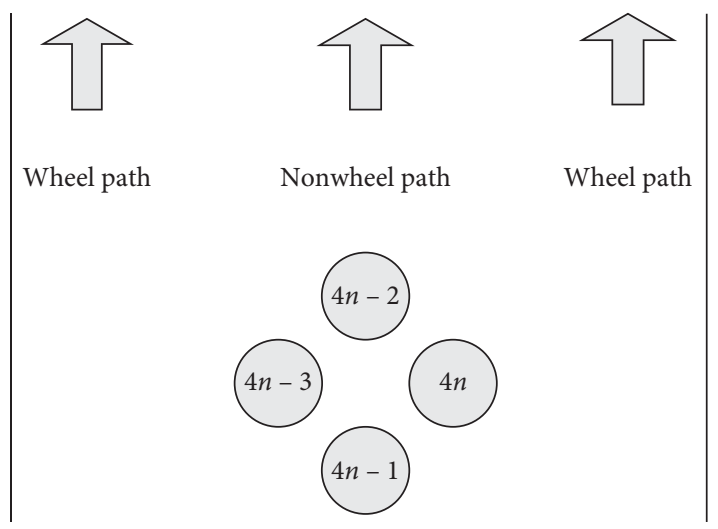

Figure 1: Core distribution in a transverse section.

mechanical testing, they were further used for the extraction and sieving test. Aggregate gradations and binder content of each layer are shown in Table 1.

As shown in the original material design data, the material designation of the middle and bottom layers was the same. However, there were some differences in binder content and aggregate gradation, which might be mainly due to the quantity limitation of the cores and construction factors in the paving process.

2.3. Specimen Information. The cores from the field were fabricated into different specimens, which were the top asphalt layer $(\mathrm{T})$, middle asphalt layer $(\mathrm{M})$, bottom asphalt layer (B), top and middle asphalt layers (TM), and middle and bottom asphalt layers (MB), respectively. The structure of the specimen is as illustrated in Figure 2. The information of specimens is shown in Table 2, where groups 1 to 9 are used for the HWTT and group 10 is used for the dynamic modulus test.

\section{Test Methods}

\subsection{The Hamburg Wheel-Tracking Test (HWTT)}

3.1.1. The HWTT Process. Generally, the HWTT is utilized for characterizing the rutting resistance potential and moisture damage potential of the asphalt mixture in the laboratory. The HWTT is conducted following AASHTO T 324 [39]. Typically, two cylindrical specimens are submerged in a water bath at a constant temperature of $50 \pm 2^{\circ} \mathrm{C}$ and subjected to a steel wheel by 52 passes/min. The HWTT passfail criteria are based on a maximum rutting depth of $10 \mathrm{~mm}$ and the number of load passes of 20000, whichever comes first. The HWTT of field specimens is conducted under different test conditions, as shown in Figure 3.

3.1.2. Test Conditions of the HWTT. The HWTT is conducted at $50^{\circ} \mathrm{C}$ under the wet condition, which may not adequately evaluate the rutting performance of the HMA, and $60^{\circ} \mathrm{C}$ under the dry condition, which is a supplementary test condition [21, 40]. Actually, the rutting performance of the AC pavement is closely related to the local weather conditions, especially under high temperature and rain.

The everyday highest temperature and rainfall in the Chongqing area could be obtained from the China Integrated Meteorological Information Service System (CIMISS) [41]. The highest temperature and cumulative rainfall of each month between 2014 and 2018 were analyzed. The number of hot days (the temperature exceeds $30^{\circ} \mathrm{C}$ ) and the highest temperature of each year are shown in Figure 4 . The cumulative rainfall of each month between 2014 and 2018 is presented in Figure 5.

As shown in Figure 4, the highest temperature of the past five years exceeded $38^{\circ} \mathrm{C}$ in Chongqing. In the years of 2014, 2016 , and 2017 , the highest temperature exceeded $40^{\circ} \mathrm{C}$. In addition, the number of hot days reached a minimum of nearly 70 in 2018 and a maximum of 115 in 2017. As presented in Figure 5, the rain mainly fell between April and October, and particularly in June and September. Obviously, high-temperature days were accompanied by rainy weather. Therefore, in the Chongqing area, both high temperature and rainy weather needed to be considered when evaluating the rutting performance.

According to Gerald [41], the highest temperature of the pavement surface could be calculated by the following equation:

$$
T_{\mathrm{s}}=T_{\mathrm{a}}-0.00618 \mathrm{Lat}^{2}+0.2289 \mathrm{Lat}+24.4,
$$

where $T_{\mathrm{s}}$ is the highest temperature of the pavement surface, ${ }^{\circ} \mathrm{C}$; $\mathrm{T}_{\mathrm{a}}$ is the highest air temperature, ${ }^{\circ} \mathrm{C}$; and Lat is the latitude, .

The highest temperature in any depth of the pavement structure could be obtained by the following equation:

$$
\begin{aligned}
T_{\mathrm{d}(\max )}= & \left(T_{s(\max )}+17.78\right)\left(1-2.48 \times 10^{-3} d+1.085\right. \\
& \left.\times 10^{-5} d^{2}-2.441 \times 10^{-8} d^{3}\right)-17.78,
\end{aligned}
$$

where $T_{\mathrm{d}(\max )}$ is the highest temperature of the pavement structure at a given depth, ${ }^{\circ} \mathrm{C} ; T_{\mathrm{s}(\max )}$ is the highest temperature of the pavement surface, ${ }^{\circ} \mathrm{C}$; and $d$ is the depth of the given position in the pavement structure, $\mathrm{mm}$.

According to equations (1) and (2), the highest temperature at different depth in the pavement could be calculated, which is demonstrated in Table 3. Based on the literature [42], the highest temperature of the pavement surface on rainy days under the highest air temperature is shown in Table $3.0 \mathrm{~cm}$ was the pavement surface, and $2 \mathrm{~cm}$, $7 \mathrm{~cm}$, and $13 \mathrm{~cm}$ were the middle position of each asphalt layer, respectively.

As presented in Table 3, when the depth was between $0 \mathrm{~cm}$ and $2 \mathrm{~cm}$, the temperature ranged from $60.6^{\circ} \mathrm{C}$ to $68.5^{\circ} \mathrm{C}$. The temperature was between $53.7^{\circ} \mathrm{C}$ and $57.4^{\circ} \mathrm{C}$ at the depth of $7 \mathrm{~cm}$. At a deeper depth of $13 \mathrm{~cm}$, the temperature varied from $48.5^{\circ} \mathrm{C}$ to $51.9^{\circ} \mathrm{C}$. Moreover, the highest temperature of the surface of the pavement on rainy days was between $48.3^{\circ} \mathrm{C}$ and $53.5^{\circ} \mathrm{C}$. The actual weather condition for each $\mathrm{AC}$ layer was different: $50 \pm 2^{\circ} \mathrm{C}$ in the water condition as the HWTT condition was not accurate to evaluate the rutting performance. Therefore, the laboratory 
TABle 1: Aggregate gradations and binder content of each layer.

\begin{tabular}{lccc}
\hline $\begin{array}{l}\text { Mixture types, binder content } \\
\text { Sieve size (mm) }\end{array}$ & AC-13 top layer, 4.5\% & $\begin{array}{c}\text { AC-20 middle layer, } 4.2 \% \\
\text { Passing percent }\end{array}$ & $\begin{array}{c}\text { AC-20 bottom layer, } 4.1 \% \\
16.5\end{array}$ \\
19 & 100 & 100 & 100 \\
16 & 100 & 99.1 & 95.5 \\
13.2 & 100 & 91.7 & 86.4 \\
9.5 & 97.6 & 78.7 & 78.2 \\
4.75 & 73.7 & 66.1 & 55.6 \\
2.36 & 47.2 & 43.2 & 36.4 \\
1.18 & 33.3 & 28.7 & 23.4 \\
0.6 & 23.3 & 21 & 16.2 \\
0.3 & 15.1 & 13.9 & 9.3 \\
0.15 & 10.3 & 9.8 & 6.5 \\
0.075 & 8.5 & 8.1 & 5.1 \\
\hline
\end{tabular}

AC-13/20: dense graded asphalt mixture with a nominal maximum aggregate size (NMAS) of 13.2/20 mm.

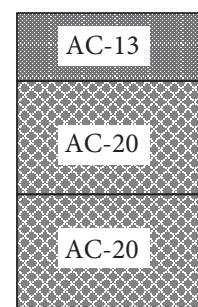

(a)

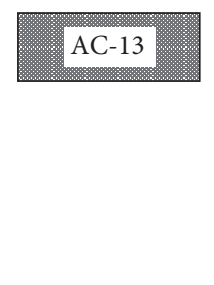

(b)

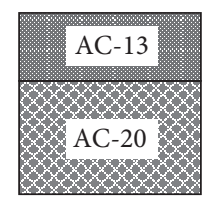

(c)

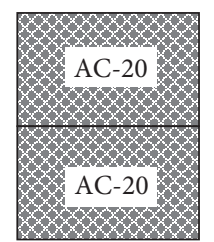

(d)

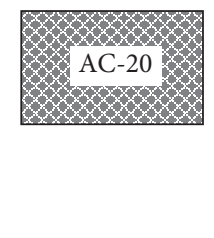

(e)

Figure 2: Specimen composition. (a) Pavement. (b) T (top AC layer). (c) TM (top and middle AC layers). (d) MB (middle and bottom AC layers). (e) M (middle AC layer) and B (bottom AC layer).

test condition should be determined by the actual weather condition. In order to analyze the rutting performance of each layer under the fully considered test conditions, four main test conditions were taken into account, namely, $50^{\circ} \mathrm{C}$ in the water condition $\left(50^{\circ} \mathrm{C}\right.$-water $), 55^{\circ} \mathrm{C}$ in the water condition $\left(55^{\circ} \mathrm{C}\right.$-water $), 60^{\circ} \mathrm{C}$ in the dry condition $\left(60^{\circ} \mathrm{C}\right.$ dry), and $65^{\circ} \mathrm{C}$ in the dry condition $\left(65^{\circ} \mathrm{C}\right.$-dry). Test conditions of different specimens for the HWTT are as illustrated in Table 4.

3.2. The Dynamic Modulus Test. Dynamic modulus is essentially the normal value of complex modulus. The value is obtained by dividing the maximum (peak-to-peak) stress by the recoverable (peak-to-peak) axial strain for the HMA material subject to a sinusoidal loading, as evident in equation (3). The average diameter of the test specimen shall be between 100 and $104 \mathrm{~mm}$ with a standard deviation of $1.0 \mathrm{~mm}$. The average height of the test specimen shall be between 147.5 and $152.5 \mathrm{~mm}$. The typical laboratory test conditions consist of five test temperatures, namely, $-10^{\circ} \mathrm{C}$, $4.4^{\circ} \mathrm{C}, 21.1^{\circ} \mathrm{C}, 37.8^{\circ} \mathrm{C}$, and $54^{\circ} \mathrm{C}$, each at six loading frequencies of $0.1 \mathrm{~Hz}, 0.5 \mathrm{~Hz}, 1.0 \mathrm{~Hz}, 5 \mathrm{~Hz}, 10 \mathrm{~Hz}$, and $25 \mathrm{~Hz}$, respectively [43].

$$
\left|E^{*}\right|=\frac{\sigma_{0}}{\varepsilon_{0}}
$$

where $\sigma_{0}$ is the peak compressive axial stress and $\varepsilon_{0}$ is the corresponding peak compressive axial resilient strain.

According to AASHTO R 62-13, the master curve of HMA could be developed by using the time-temperature superposition principle. The following equation presents the generalized form of a dynamic modulus master curve [44]:

$$
\log \left|E^{*}\right|=\delta+\frac{(\alpha)}{1+e^{\beta+\gamma \log f_{\mathrm{r}}}} .
$$

$f_{\mathrm{r}}$ is the reduced frequency expressed as

$$
\log f_{\mathrm{r}}=\log f+a_{1}\left(T_{\mathrm{R}}-T\right)+a_{2}\left(T_{\mathrm{R}}-T\right)^{2},
$$

where $E^{*}$ is the dynamic modulus; $\alpha, \beta, \delta, \gamma, a_{1}$, and $a_{2}$ are the fitting parameters; $f_{\mathrm{r}}$ is the reduced frequency at the reference temperature; $f$ is the loading frequency at the test temperature; $T_{\mathrm{R}}$ is the reference temperature; and $T$ is the test temperature. $21.1^{\circ} \mathrm{C}$ was used as the reference temperature.

The specimen thickness of the top AC layer, middle AC layer, and bottom AC layer was $4 \mathrm{~cm}, 6 \mathrm{~cm}$, and $6 \mathrm{~cm}$, respectively. One of our goals was to investigate $\left|E^{*}\right|$ of the fullthickness AC layers. The measured stress and strain could cover each of the AC layers, and $\left|E^{*}\right|$ could be regarded as representative of the full-thickness AC layers in this study. The distribution of the LVDT in each layer was about 
TABLE 2: Information of specimens.

\begin{tabular}{|c|c|c|c|}
\hline $\begin{array}{l}\text { Group } \\
\text { number }\end{array}$ & $\begin{array}{l}\text { Test } \\
\text { group }\end{array}$ & $\begin{array}{c}\text { Compaction } \\
\text { degree }(\%)\end{array}$ & $\begin{array}{c}\text { Specimen } \\
\text { height }(\mathrm{mm})\end{array}$ \\
\hline \multirow{4}{*}{1} & $\mathrm{~T}-1-1^{(1)}$ & 98.10 & 42.50 \\
\hline & $\mathrm{T}-1-2$ & 96.13 & 41.85 \\
\hline & $\mathrm{T}-2-1$ & 97.21 & 41.85 \\
\hline & $\mathrm{T}-2-2$ & 94.44 & 41.25 \\
\hline \multirow{4}{*}{2} & $\mathrm{~T}-5-1$ & 98.40 & 44.50 \\
\hline & $\mathrm{T}-5-2$ & 94.63 & 43.25 \\
\hline & T-6-1 & 99.77 & 39.25 \\
\hline & $\mathrm{T}-6-2$ & 97.85 & 40.00 \\
\hline \multirow{4}{*}{3} & B-5-1 & 96.38 & 40.20 \\
\hline & B-5-2 & 94.16 & 39.35 \\
\hline & B-6-1 & 96.93 & 36.40 \\
\hline & B-6-2 & 95.95 & 37.05 \\
\hline \multirow{4}{*}{4} & MB-1-1 & $\mathrm{N} / \mathrm{A}^{(3)}$ & 101.25 \\
\hline & MB-1-2 & N/A & 101.80 \\
\hline & MB-2-1 & N/A & 101.95 \\
\hline & MB-2-2 & N/A & 102.00 \\
\hline \multirow{4}{*}{5} & $\mathrm{~T}-3-1$ & 97.00 & 38.45 \\
\hline & $\mathrm{T}-3-2$ & 95.21 & 38.60 \\
\hline & T-4-1 & 98.35 & 42.85 \\
\hline & $\mathrm{T}-4-2$ & 97.13 & 41.95 \\
\hline \multirow{4}{*}{6} & TM-7-1 & N/A & 100.90 \\
\hline & TM-7-2 & N/A & 101.70 \\
\hline & TM-8-1 & N/A & 101.40 \\
\hline & TM-8-2 & N/A & 101.20 \\
\hline \multirow{4}{*}{7} & B-7-1 & 97.86 & 41.70 \\
\hline & B-7-2 & 97.22 & 42.25 \\
\hline & B-8-1 & 98.06 & 42.25 \\
\hline & B-8-2 & 96.54 & 41.85 \\
\hline \multirow{4}{*}{8} & M-5-1 & 96.98 & 60.50 \\
\hline & M-5-2 & 95.97 & 59.60 \\
\hline & M-6-1 & 96.92 & 59.65 \\
\hline & M-6-2 & 95.77 & 59.20 \\
\hline \multirow{4}{*}{9} & MB-3-1 & N/A & 101.50 \\
\hline & MB-3-2 & N/A & 101.55 \\
\hline & MB-4-1 & $\mathrm{N} / \mathrm{A}$ & 102.10 \\
\hline & MB-4-2 & N/A & 101.30 \\
\hline \multirow{5}{*}{10} & E-9-1 ${ }^{(2)}$ & $\mathrm{N} / \mathrm{A}$ & 150.84 \\
\hline & E-9-2 & N/A & 150.64 \\
\hline & E-9-3 & N/A & 150.46 \\
\hline & E-10-1 & N/A & 149.55 \\
\hline & E-10-2 & N/A & 149.53 \\
\hline
\end{tabular}

(1) T indicates the test specimen is the top asphalt layer of the core, which could be recognized from Figure 2. The first Arabic number 1 indicates the test specimen was drilled from number 1 transverse section of the pavement. The second Arabic number 1 indicates the test specimen is the first specimen in transverse section, and the Arabic number of group 10 has the same meaning as the above. Moreover, others could be understood in terms of this example. (2) E indicates the specimen is used for the dynamic modulus test. (3) Because the groups 4, 6, 9, and 10 are composed of different AC layers, the compaction degree could not be measured, so it is expressed as "N/A" in the table.

$H_{t}=25 \mathrm{~mm}, H_{m}=60 \mathrm{~mm}$, and $H_{b}=15 \mathrm{~mm}$, as shown in Figure 6(a). Another purpose was to study $\left|E^{*}\right|$ of the middle and bottom AC layers. The distribution of the LVDT in each layer was about $H_{m}=50 \mathrm{~mm}$ and $H_{b}=50 \mathrm{~mm}$, as presented in Figure 6(b). The dynamic modulus test setup is illustrated in Figure 6(c).

\section{Results and Discussion}

\subsection{HWTT Result}

4.1.1. Rutting Depth and the Recommendation of Test Conditions. The rutting depth and rutting curves of different specimens were different within four kinds of test conditions, as demonstrated in Figure 7. When the material type and the specimen height were the same, the higher the temperature, the deeper the rutting depth, as shown in Figures 7(a)-7(d). B-5-1, B-5-2, B-6-1, and B-6-2 showed three stages of the rutting process before 10000 loading cycles under $55^{\circ} \mathrm{C}$ in the water condition, while T-5-1, T-6-1, T-5-2, and T-6-2 had the first two stages after 20000 loading cycles, as illustrated in Figure $7(\mathrm{c})$. The modified asphalt binder could significantly improve the rutting resistance performance of the asphalt mixture, and compared to other rutting test conditions, $55^{\circ} \mathrm{C}$ in water might be the most severe test condition. However, the asphalt type of B-5-1, B-5-2, B-6-1, and B-6-2 was the base asphalt binder, and the test condition was $55^{\circ} \mathrm{C}$ in water, which might be the reason that rutting performance of B-5-1, B-5-2, B-6-1, and B-6-2 was greatly different from that of the other specimens. Moreover, compared to Figure $7(\mathrm{a}), 55^{\circ} \mathrm{C}$ in the water condition was more suitable to evaluate the rutting performance of the top AC layer. As presented in Figure 7(d), rutting depth was influenced by specimen height and rutting depth would be shallower with the thicker specimen, which also manifested that the rutting resistance performance could be enhanced by increasing the thickness of the asphalt layer.

Based on trial and error, rutting curves between loading cycles 6000 and 20000 could be fitted by straight lines well, which are demonstrated in Figure 7, except that B-5-1, B-6$1, \mathrm{~B}-5-2$, and B-6-2 appeared the third rutting stage within 10000 loading cycles. Fitting equations and $R^{2}$ values are illustrated in Table 5. The $R^{2}$ values were greater than 0.95 , which indicated that the simulation results had a strong correlation with the rutting curves. Therefore, the rutting depth at 20000 loading cycles could be predicted by using a fitting line between 6000 and 10000 (or smaller) loading cycles. It also could be inferred that concerning the time consumption and energy-saving, the test should be stopped at the loading cycles of 10000 or even smaller loading cycles.

The average rutting depth of each group and coefficient of variation (CV) value of the rutting depth are illustrated in Table 6. The average rutting depth of each group was the representative value of the same asphalt layers under the same test condition and specimen height. It was evident that rutting depths of different AC layers vary greatly under four different kinds of test conditions. The top AC layer was directly in contact with the traffic loading and weather condition, which could have a great impact on the $\mathrm{CV}$ values. CV values of groups 5 and 6 exceeded 20\%, which may be because the two groups contained the top AC layer, while the other $\mathrm{CV}$ values were acceptable.

Considering the actual field conditions, compared to the middle and bottom AC layers, the influence of the high 


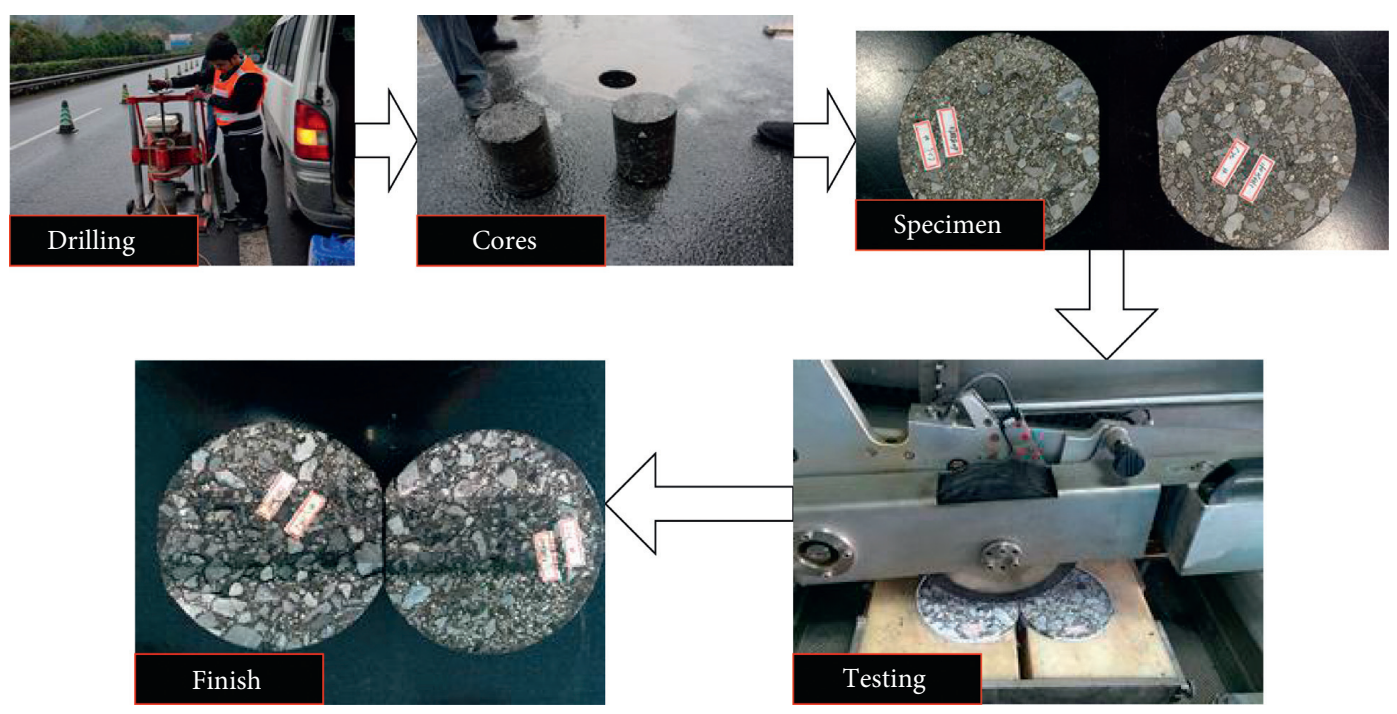

FIGURE 3: HWTT process of the field cores.

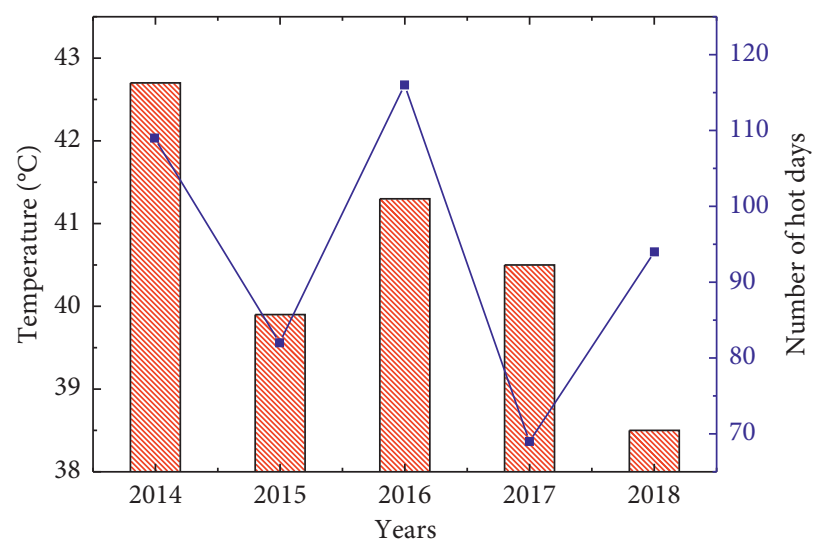

Highest temperature - - Number of hot days

FIgURE 4: The highest temperature and the number of hot days.

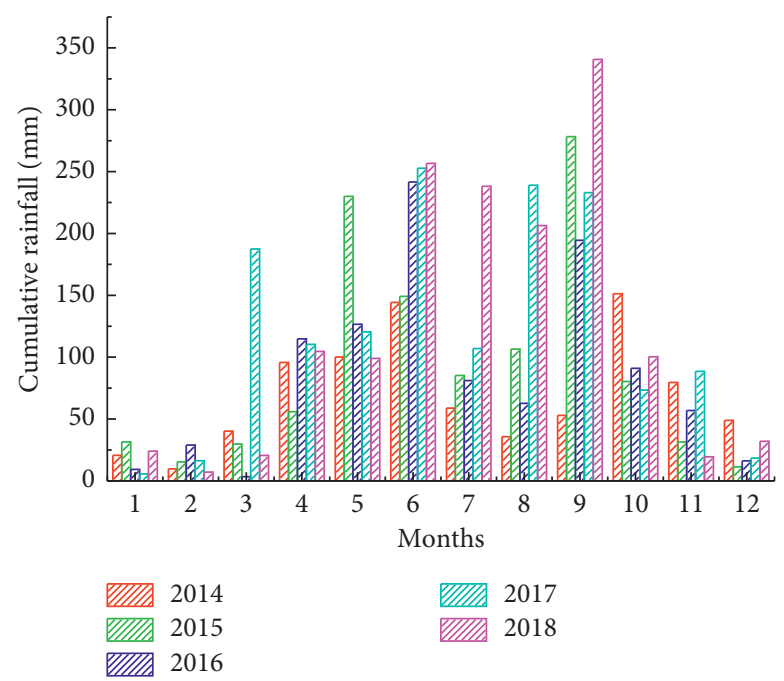

FIGURE 5: Cumulative rainfall of each month. 
Table 3: The highest temperature at different depth in the pavement (unit: ${ }^{\circ} \mathrm{C}$ ).

\begin{tabular}{llllll}
\hline Year & $0 \mathrm{~cm}$ & $2 \mathrm{~cm}$ & $7 \mathrm{~cm}$ & $13 \mathrm{~cm}$ & The highest temperature of the surface on rainy days \\
\hline 2014 & 68.5 & 64.6 & 57.4 & 51.9 & 53.5 \\
2015 & 65.7 & 61.9 & 54.9 & 49.6 & 50.0 \\
2016 & 67.1 & 63.2 & 56.2 & 50.7 & 51.8 \\
2017 & 66.3 & 62.5 & 55.5 & 50.1 & 50.8 \\
2018 & 64.3 & 60.6 & 53.7 & 48.5 & 48.3 \\
\hline
\end{tabular}

TABle 4: Test conditions of different specimens.

\begin{tabular}{lc}
\hline Group number & Test condition \\
\hline 1 & $50^{\circ} \mathrm{C}$-water \\
2 & $55^{\circ} \mathrm{C}$-water \\
3 & $55^{\circ} \mathrm{C}$-water \\
4 & $60^{\circ} \mathrm{C}$-dry \\
5 & $65^{\circ} \mathrm{C}$-dry \\
6 & $65^{\circ} \mathrm{C}$-dry \\
7 & $65^{\circ} \mathrm{C}$-dry \\
8 & $65^{\circ} \mathrm{C}$-dry \\
9 & $65^{\circ} \mathrm{C}$-dry \\
\hline
\end{tabular}

temperature and rain on the top AC layer was more significant and high temperature in the dry/water condition should be considered. As shown in Table 6, incorporating the actual weather conditions, groups 1, 2, 5, and 6 showed that $50^{\circ} \mathrm{C}$ in the water condition could not comprehensively evaluate the rutting performance, and both high temperature in the dry condition $\left(65^{\circ} \mathrm{C}\right)$ and high temperature in the water condition $\left(55^{\circ} \mathrm{C}\right)$ were necessary for evaluating the rutting performance of the top AC layer. In accordance with the impermeability requirement of the asphalt mixture in China, it was reasonable to evaluate the rutting performance of the middle and bottom AC layers in the dry condition. Moreover, according to the rutting results of groups 4,7 , 8 , and $9,60^{\circ} \mathrm{C}$ in the dry condition was acceptable as the test condition for the rutting performance evaluation of the middle and bottom AC layers. Based on the analysis results above, and the actual highest temperature at different AC depth, as illustrated in Table 3, the test condition was recommended as follows:

(1) HWTT test condition for the top AC layer: $55^{\circ} \mathrm{C}$ in the water condition and $65^{\circ} \mathrm{C}$ in the dry condition were recommended.

(2) HWTT test condition for the middle and bottom AC layers: when the top AC layer was the dense graded asphalt mixture, $60^{\circ} \mathrm{C}$ in the dry condition was recommended; for the permeable top AC layer, $50^{\circ} \mathrm{C}$ in the water condition and $60^{\circ} \mathrm{C}$ in the dry condition were proposed.

4.1.2. Analysis of Different Factors of the Rutting Depth. The effect of the compaction degree, specimen height, mixture type, and test condition on rutting depth was investigated. "Compaction" represented the compaction degree (Table 2), "Height" represented the specimen height (Table 2), "Condition" represented the test condition,
"Material" represented the mixture type, and "Rutting" represented the rutting depth. Figure 8 shows the scatter plot of the relationship between factors and rutting depth (Figure 7). Since the "Material" and "Condition" could not be described directly, the Arabic numbers were used instead. For the test condition, " 1 " represented $50^{\circ} \mathrm{C}$ in the water condition, " 2 " represented $65^{\circ} \mathrm{C}$ in the dry condition, and " 3 " represented $55^{\circ} \mathrm{C}$ in the water condition. For the mixture type, " 4 " represented AC- 13 and " 5 " represented AC-20. It should be noticed that only groups " $1,2,3,5,7$, and 8 " in Table 2 were chosen for analysis, and only one material type was contained in the groups.

As demonstrated in Figure 8, the rutting depth decreased when the "Material" increased, and the top AC layer had better rutting resistance than middle and bottom AC layers. Although the NMAS of AC-13 was smaller than that of AC-20, the modified asphalt binder enhanced the rutting performance of the asphalt mixture. Compared to $65^{\circ} \mathrm{C}$ in the dry condition, $55^{\circ} \mathrm{C}$ in the water condition was more likely to cause rutting. Therefore, in hot areas, particularly the areas with high temperature and rainy days (i.e., Chongqing area), the rutting performance should be evaluated under the high-temperature and water conditions. In addition, rutting depth decreased with the increasing specimen height. Based on the distribution of specimen thickness along the rutting depth, when the specimen height was $4 \mathrm{~cm}$, the test results of the rutting depth were distributed discretely. $6 \mathrm{~cm}$ was more suitable as the specimen height for the HWTT. Moreover, the compaction degree was one of the most important factors as the construction quality control, and rutting depth decreased a little as the compaction degree increased from $94 \%$ to $99 \%$. It is worth to notice that $94 \%$ was the control threshold of the compaction degree that satisfied the construction specification of China [38]. It could be inferred that, with the scientific asphalt mixture design and good construction quality control, the compaction degree had little influence on rutting performance when it met the specification requirement.

The linear correlation between the rutting depth and factors was calculated, and the linear correlation coefficient between rutting depth and "Compaction," "Height," "Material," and "Condition" was $-0.1,-0.33,0.47$, and 0.63, respectively. It could be concluded that the test condition had the most significant influence on the HWTT result, followed by the mixture type, specimen height, and compaction degree, respectively. Furthermore, the rutting performance of the AC layer could be improved by increasing the compaction degree, the thickness of the AC layer, and the material type chosen. 


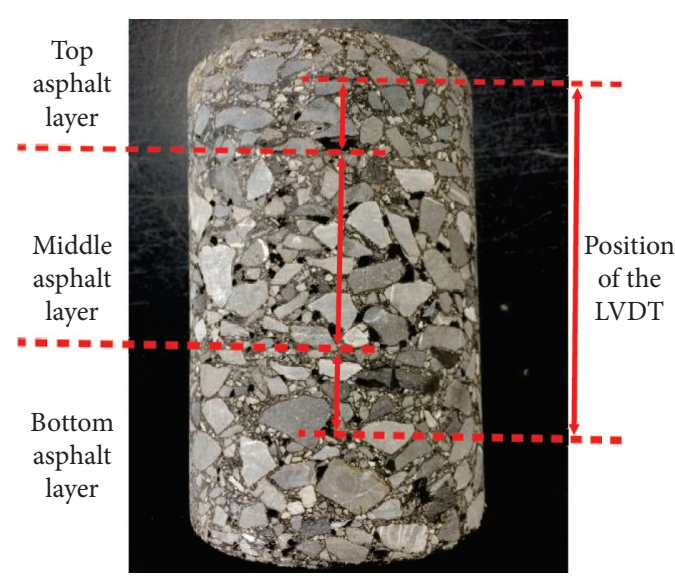

(a)

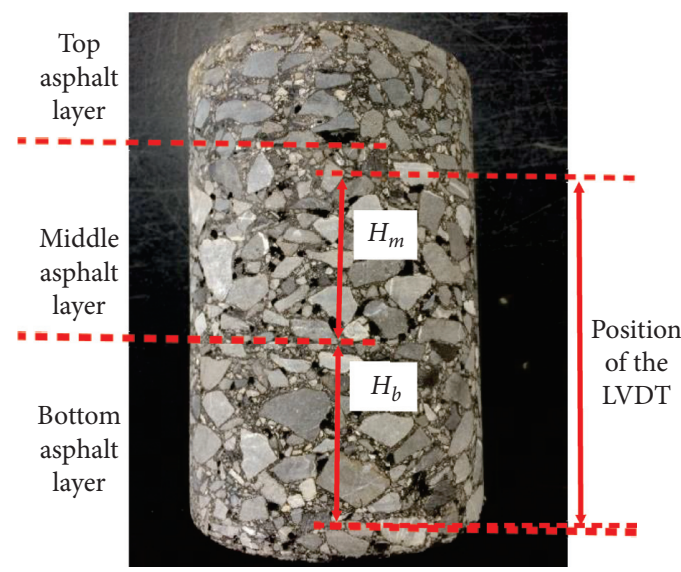

(b)

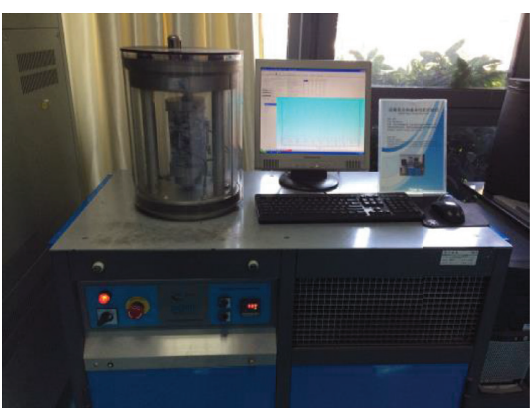

(c)

Figure 6: Dynamic modulus test: (a) location of the LVDTs for E-9-1, E-9-2, and E-9-3; (b) location of the LVDTs for E-10-1 and E-10-2; (c) test setup.
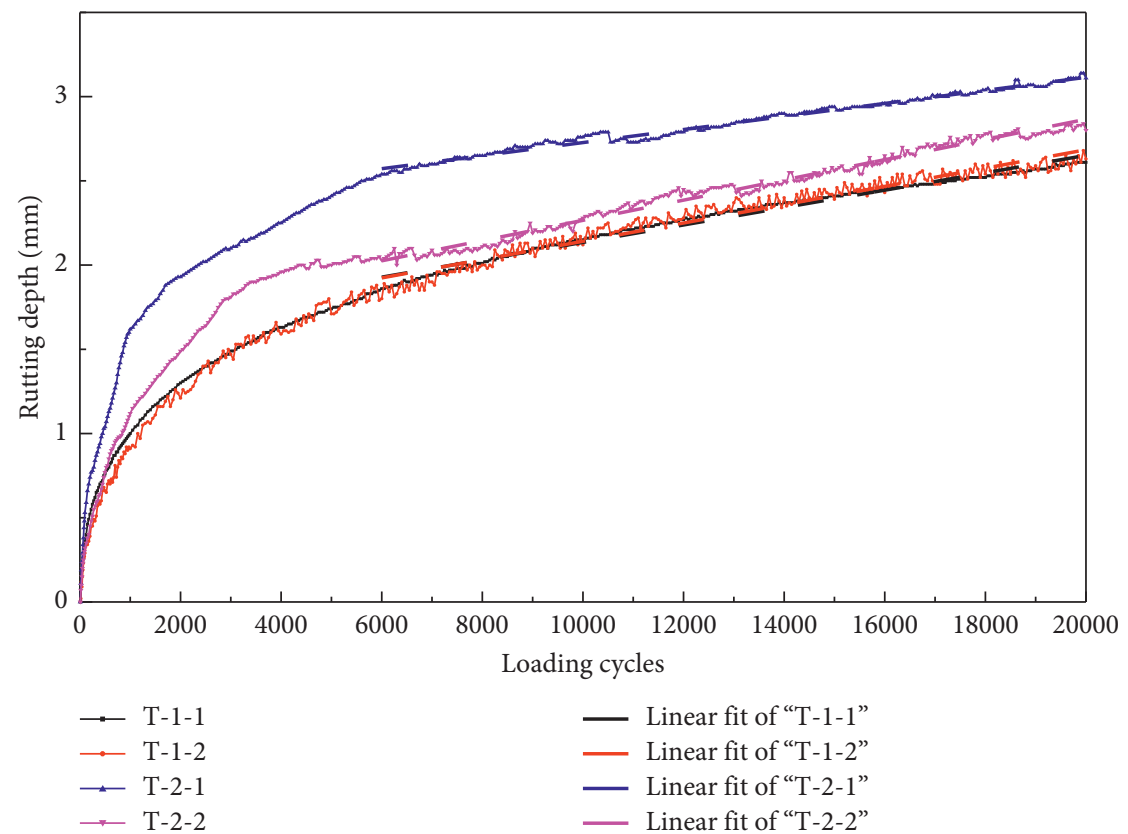

__ Linear fit of "T-1-1"

- Linear fit of "T-1-2"

_ Linear fit of "T-2-1"

__ Linear fit of “T-2-2”

(a)

Figure 7: Continued. 

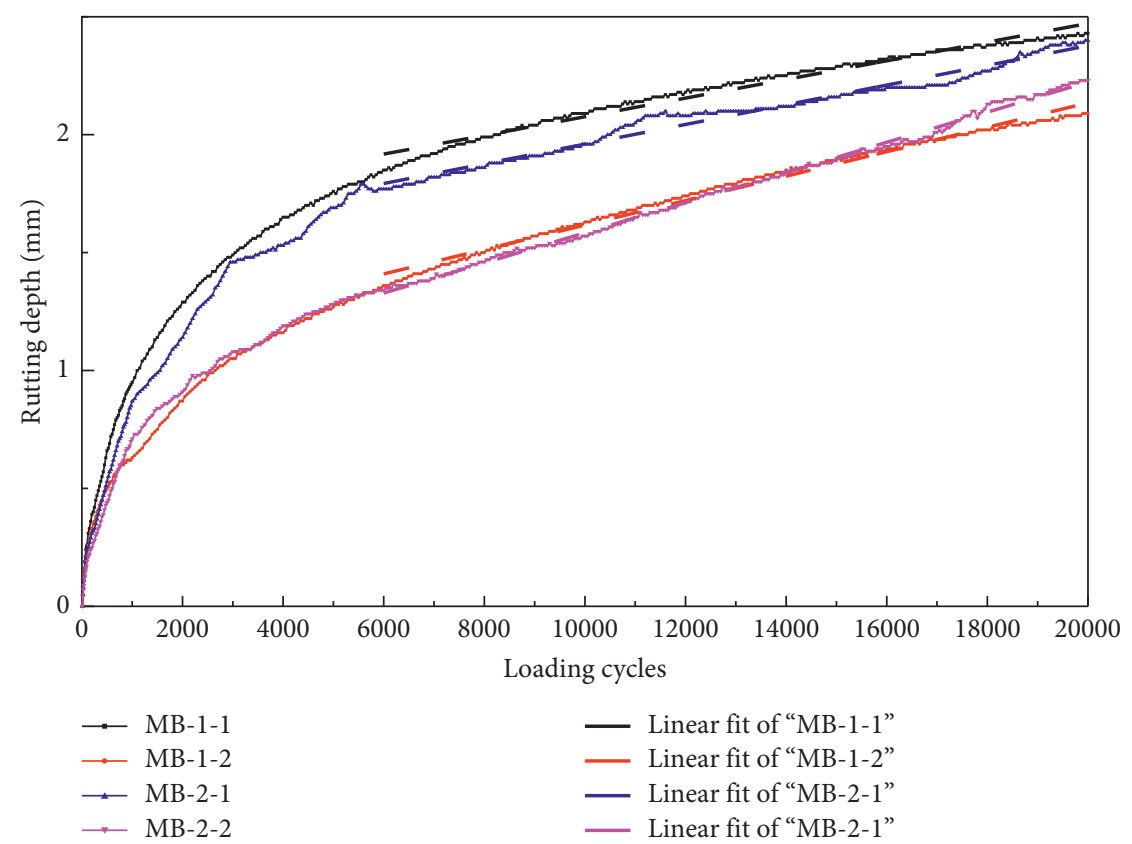

(b)

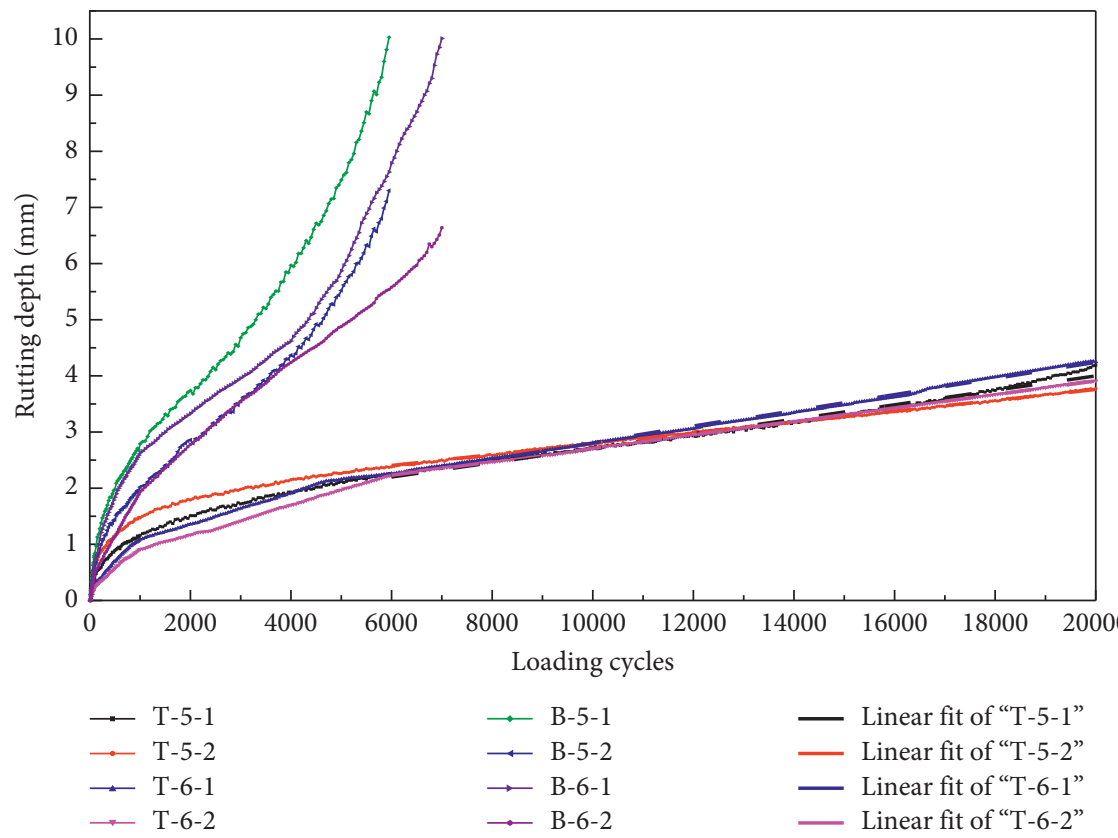

(c)

Figure 7: Continued. 


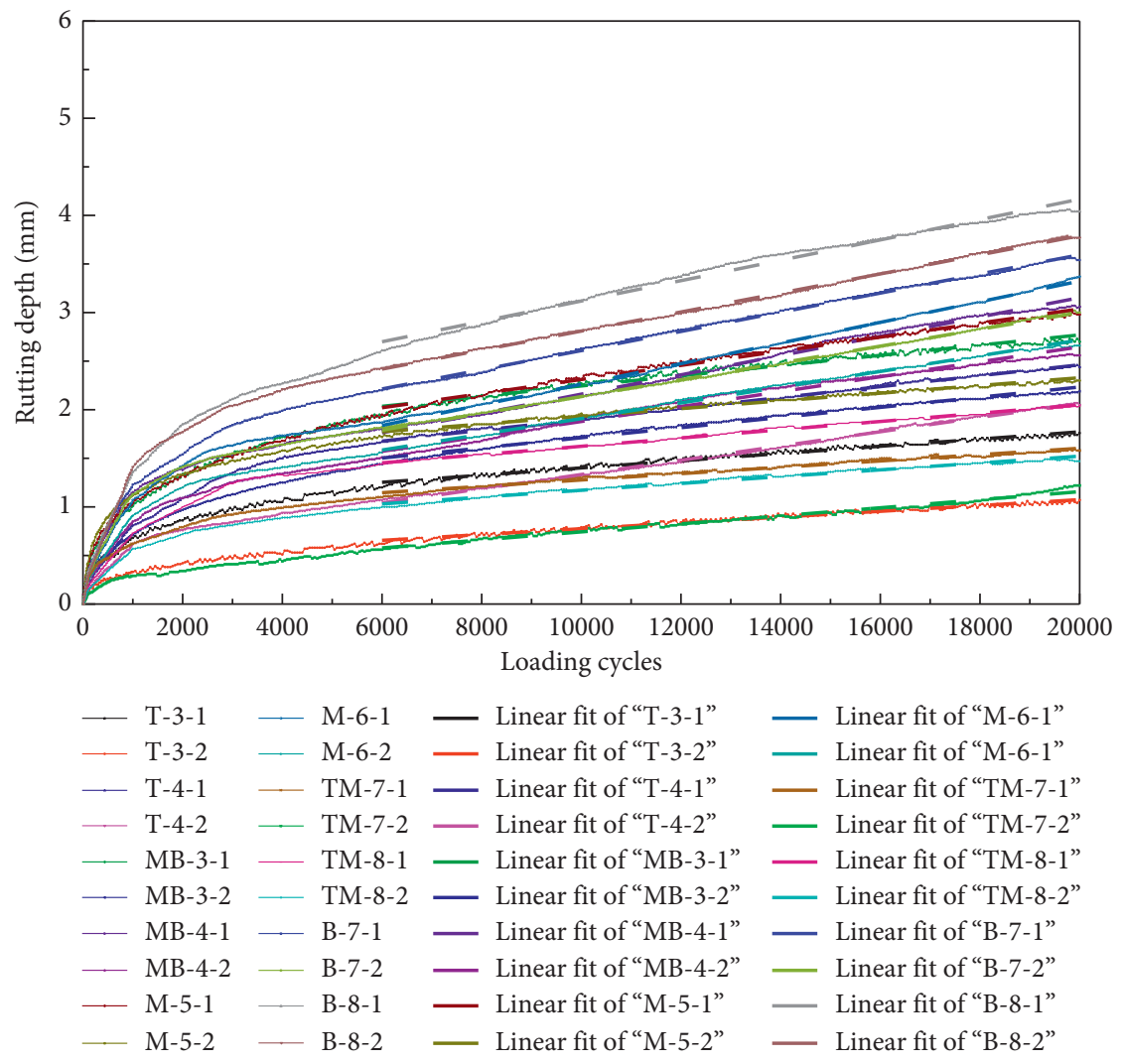

(d)

Figure 7: Rutting curves for varying specimens under different test conditions: (a) $50^{\circ} \mathrm{C}$-water; (b) $60^{\circ} \mathrm{C}$-dry; (c) $55^{\circ} \mathrm{C}$-water; (d) $65^{\circ} \mathrm{C}$-dry.

4.1.3. Contribution of Each Layer under $65^{\circ} \mathrm{C}$ in the Dry Condition. As previously demonstrated by HWTT results, the rutting depth of each AC layer was different, and actually, the function of each layer was different. The contribution of each AC layer to rutting depth was calculated by the following equation:

$$
R=\frac{\mathrm{RD}_{\mathrm{X}}}{\mathrm{RD}_{\mathrm{T}}+\mathrm{RD}_{\mathrm{M}}+\mathrm{RD}_{\mathrm{B}}} * 100 \%,
$$

where $R$ represents the layer of interest which contributes to rutting depth; $\mathrm{RD}_{\mathrm{X}}$ represents the rutting depth of the $\mathrm{AC}$ layer of interest; and $\mathrm{RD}_{\mathrm{T}}, \mathrm{RD}_{\mathrm{M}}$, and $\mathrm{RD}_{\mathrm{B}}$ represent the rutting depth of the top AC layer, middle AC layer, and bottom AC layer, respectively.

The specimens of groups " 5,7 , and 8 " were under the dry condition at $65^{\circ} \mathrm{C}$, which were used for rutting contribution analysis. Additionally, the pavement structure was formed by the specimen with the same last Arabic number of each test group number. Two specimens were contained in each AC layer. The rutting contribution of the top AC layer, middle AC layer, and bottom AC layer was calculated by equation (6), as shown in Table 7.

As presented in Table 7, the rutting contribution of each layer was calculated, and it could be obtained that the bottom AC layer had the most significant influence on the rutting performance of the full-thickness AC layers, followed by middle and top AC layers. The conclusion was consistent with prior researches $[36,37]$. Therefore, in the process of asphalt pavement structure design, it was more important to focus on the material selection, design, and construction quality control of the middle and bottom AC layers.

4.2. Dynamic Modulus Test Result. The $\left|E^{*}\right|$ master curve could be obtained by utilizing equations (4) and (5), as illustrated in Figure 9. According to equation (5), the high temperatures corresponded to the low loading frequency range and the low temperatures were equivalent to the high loading frequency range. As demonstrated in Figure 9, in the high-temperature domain, the rutting performance ranking in terms of the $\left|E^{*}\right|$ values was as follows: E-9-2, E-9-1, E-9-3, E-10-2, and E-10-1. The $\left|E^{*}\right|$ value ranking was E-9-3, E-9-1, E-9-2, E-10-2, and E-10-1 in low temperature. Considering that E-9-3, E-9-1, and E-9-2 consisted of AC-13 and AC-20 and E-10-1 and E-10-2 contained AC-20, it was indicated that the $\left|E^{*}\right|$ value of $\mathrm{AC}-13$ with modified asphalt was higher than that of AC-20 with the base asphalt binder.

Witczak et al. [17] proved that the $\left|E^{*}\right|$ values at $54.4^{\circ} \mathrm{C}$ and $37.8^{\circ} \mathrm{C}$ correlated well with the rutting performance. Pellinen et al. proposed the $\left|E^{*}\right|$ value of $345 \mathrm{MPa}$ at $54.4^{\circ} \mathrm{C}$ and $5 \mathrm{~Hz}$ as a threshold to indicate a good rutting resistance performance of the HMA [45]. A tentative criterion of $241 \mathrm{MPa}$ at $50^{\circ} \mathrm{C}$ and $5 \mathrm{~Hz}$ was recommended as the indicative threshold [21]. For convenience, $241 \mathrm{MPa}$ was regarded as the threshold value at $54.4^{\circ} \mathrm{C}$ and $5 \mathrm{~Hz}$ in this 
TABLE 5: Linear fit of rutting curves between 6000 and 20000 loading cycles.

\begin{tabular}{|c|c|c|c|}
\hline \multirow{2}{*}{ Linear fit } & \multicolumn{3}{|c|}{ Equation: $y=a+b^{*} x$} \\
\hline & Intercept & Slope & $R^{2}$ \\
\hline $\mathrm{T}-1-1$ & 1.62 & $5.16 E-05$ & 0.98 \\
\hline $\mathrm{T}-1-2$ & 1.60 & $5.43 E-05$ & 0.96 \\
\hline $\mathrm{T}-2-1$ & 2.34 & $3.88 E-05$ & 0.99 \\
\hline $\mathrm{T}-2-2$ & 1.67 & $6.00 E-05$ & 0.99 \\
\hline MB-1-1 & 1.68 & $3.96 E-05$ & 0.98 \\
\hline MB-1-2 & 1.10 & $5.18 E-05$ & 0.99 \\
\hline MB-2-1 & 1.54 & $4.17 E-05$ & 0.98 \\
\hline MB-2-2 & 0.944 & $6.39 E-05$ & 1.00 \\
\hline T-5-1 & 1.43 & $1.29 E-04$ & 0.99 \\
\hline $\mathrm{T}-5-2$ & 1.82 & $9.67 E-05$ & 1.00 \\
\hline T-6-1 & 1.37 & $1.44 E-04$ & 1.00 \\
\hline $\mathrm{T}-6-2$ & 1.51 & $1.20 E-04$ & 1.00 \\
\hline $\mathrm{T}-3-1$ & 1.03 & $3.71 E-05$ & 0.98 \\
\hline $\mathrm{T}-3-2$ & 0.48 & $2.99 E-05$ & 0.98 \\
\hline $\mathrm{T}-4-1$ & 1.34 & $5.61 E-05$ & 1.00 \\
\hline $\mathrm{T}-4-2$ & 0.60 & $7.34 E-05$ & 1.00 \\
\hline MB-3-1 & 1.72 & $5.25 E-05$ & 0.98 \\
\hline MB-3-2 & 1.19 & $5.22 E-05$ & 0.99 \\
\hline MB-4-1 & 1.17 & $9.93 E-05$ & 0.99 \\
\hline MB-4-2 & 1.11 & $7.67 E-05$ & 0.98 \\
\hline M-5-1 & 1.59 & $7.26 E-05$ & 0.99 \\
\hline M-5-2 & 1.54 & $3.97 E-05$ & 0.99 \\
\hline M-6-1 & 1.20 & $1.06 E-04$ & 1.00 \\
\hline M-6-2 & 1.10 & $8.09 E-05$ & 1.00 \\
\hline TM-7-1 & 0.95 & $3.26 E-05$ & 0.99 \\
\hline TM-7-2 & 0.33 & $4.14 E-05$ & 0.99 \\
\hline TM-8-1 & 1.20 & $4.26 E-05$ & 1.00 \\
\hline TM-8-2 & 0.82 & $3.51 E-05$ & 0.99 \\
\hline B-7-1 & 1.62 & $9.86 E-05$ & 1.00 \\
\hline B-7-2 & 1.27 & $8.65 E-05$ & 1.00 \\
\hline B-8-1 & 2.07 & $1.05 E-04$ & 0.99 \\
\hline B-8-2 & 1.83 & $9.80 E-05$ & 1.00 \\
\hline
\end{tabular}

TABLE 6: The average rutting depth and CV values of each group under different test conditions.

\begin{tabular}{lcc}
\hline $\begin{array}{l}\text { Group } \\
\text { number }\end{array}$ & $\begin{array}{c}\text { Average rutting depth } \\
(\mathrm{mm})\end{array}$ & $\begin{array}{c}\text { CV of rutting depth } \\
(\%)\end{array}$ \\
\hline 1 & 2.79 & 8.30 \\
2 & 4.03 & 5.66 \\
3 & 8.70 & 17.61 \\
4 & 2.29 & 6.92 \\
5 & 1.83 & 31.60 \\
6 & 1.58 & 21.75 \\
7 & 3.59 & 12.31 \\
8 & 2.83 & 16.13 \\
9 & 2.63 & 13.69 \\
\hline
\end{tabular}

study. All the specimens were with sufficient $\left|E^{*}\right|$ values, which indicated that the rutting performance of all AC layers was in good condition, as illustrated in Figure 10.

4.3. Correlations between the Dynamic Modulus Test and the HWTT. E-9-1, E-9-2, and E-9-3 consisted of the top, middle, and bottom AC layers, and E-10-1 and E-10-2 contained the middle and bottom AC layers. $\left|E^{*}\right|$ values at the low loading frequency (equivalent to the low frequency) under $54.4^{\circ} \mathrm{C}$ are listed in Table 8 . The HWTT results of the specimens containing both the top and middle layers are shown in Table 9. As previous studies illustrated, $241 \mathrm{MPa}$ or $345 \mathrm{MPa}$ as the $\left|E^{*}\right|$ value at $54.4^{\circ} \mathrm{C}$ and $5 \mathrm{~Hz}$ could be regarded as the threshold to indicate the rutting performance [21, 45]. The following could be concluded from Tables 8 and 9:

(1) The rutting performance of all specimens could meet the requirements under $65^{\circ} \mathrm{C}$-dry. The dynamic modulus could meet the rutting requirement as the threshold value of $241 / 345 \mathrm{MPa}$ at $54.4^{\circ} \mathrm{C}$ and $5 \mathrm{~Hz}$.

(2) When $241 \mathrm{MPa}$ was chosen as the threshold for rutting performance, the dynamic modulus at $54.4^{\circ} \mathrm{C}$ and $1 \mathrm{~Hz}$ could represent the rutting performance well compared to the dynamic modulus at $54.4^{\circ} \mathrm{C}$ and $5 \mathrm{~Hz}$.

(3) E-10-1, E-10-2, and MB-3-1 and MB-3-2, MB-4-1, and MB-4-2 both contain the middle and bottom AC layers, and the material type was AC-20. Additionally, all the rutting depth was less than $10 \mathrm{~mm}$, all the dynamic modulus at $54.4^{\circ} \mathrm{C}$ and $1 \mathrm{~Hz}$ met the threshold, and it could be inferred that dynamic modulus at $54.4^{\circ} \mathrm{C}$ and $1 \mathrm{~Hz}$ could effectively 


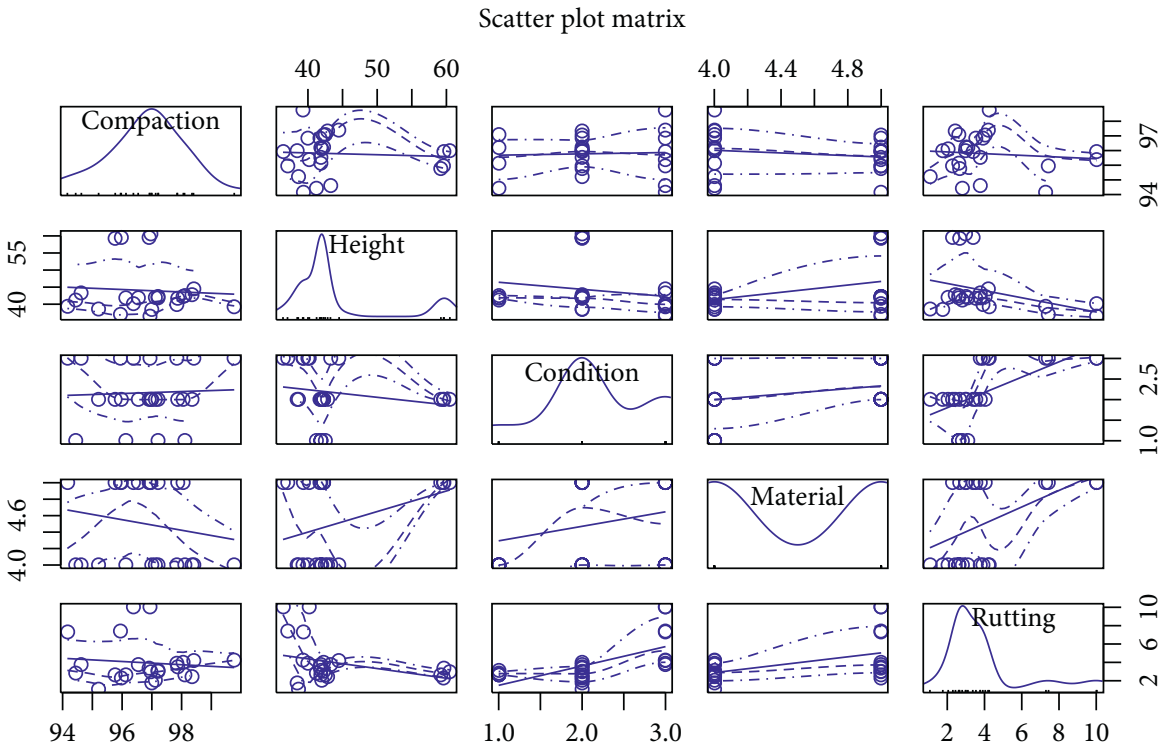

Figure 8: Scatter plot of the influence of different factors on rutting depth.

TABLE 7: $R$ of each layer.

\begin{tabular}{|c|c|c|c|c|c|c|}
\hline Test group & Average rutting depth $(\mathrm{mm})$ & $R(\%)$ & Test group & Average rutting depth $(\mathrm{mm})$ & $R(\%)$ & Average $R(\%)$ \\
\hline $\begin{array}{l}\text { T-3-2 } \\
\text { T-4-2 }\end{array}$ & 1.56 & 21.01 & $\begin{array}{l}\text { T-3-1 } \\
\text { T-4-1 }\end{array}$ & 2.1 & 23.17 & 22.09 \\
\hline $\begin{array}{l}\text { M-5-2 } \\
\text { M-6-2 }\end{array}$ & 2.48 & 33.40 & $\begin{array}{l}\text { M-5-1 } \\
\text { M-6-1 }\end{array}$ & 3.18 & 35.02 & 34.21 \\
\hline $\begin{array}{l}\text { B-7-2 } \\
\text { B-8-2 }\end{array}$ & 3.39 & 45.59 & $\begin{array}{l}\text { B-7-1 } \\
\text { B-8-1 }\end{array}$ & 3.79 & 41.81 & 43.70 \\
\hline
\end{tabular}

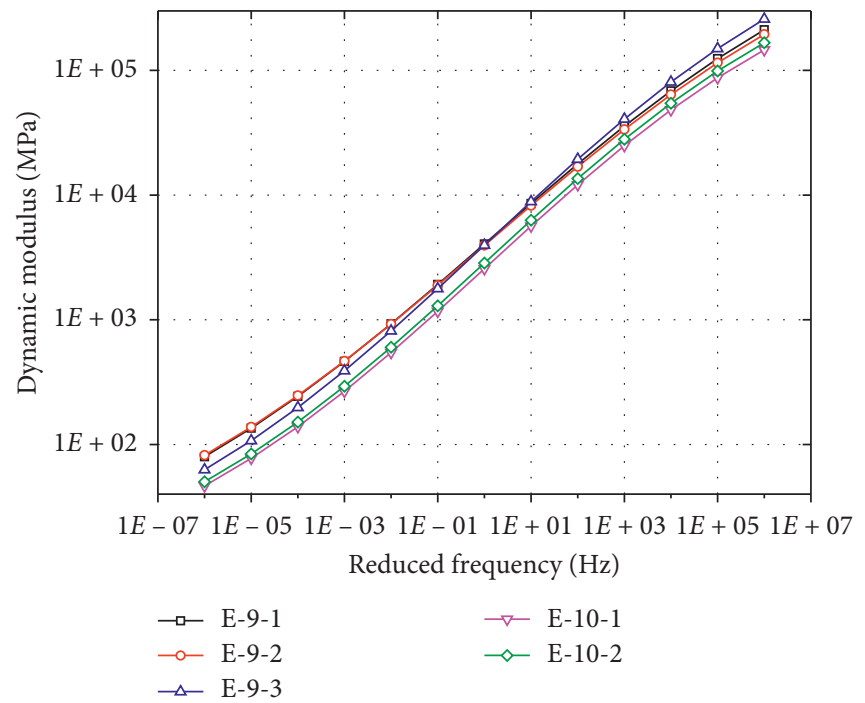

Figure 9: Dynamic modulus master curves at $21.1^{\circ} \mathrm{C}$.

represent the rutting performance of the asphalt mixture.

(4) Considering the material composition, E-9-1, E-9-2, and E-9-3 contained AC-13 and AC-20. TM-7-1, TM-7-2, TM-8-1, and TM-8-2 had the same material composition. Based on the $\left|E^{*}\right|$ values of E-9-1, E-9-2, and E-9-3 and the rutting depth of TM-7-1, TM-7-2, TM-8-1, and TM-8-2, the rutting performance of E-9-1, E-9-2, and E-9-3 was sufficient. Moreover, E-9-1, E-9-2, and E-9-3 contained the 


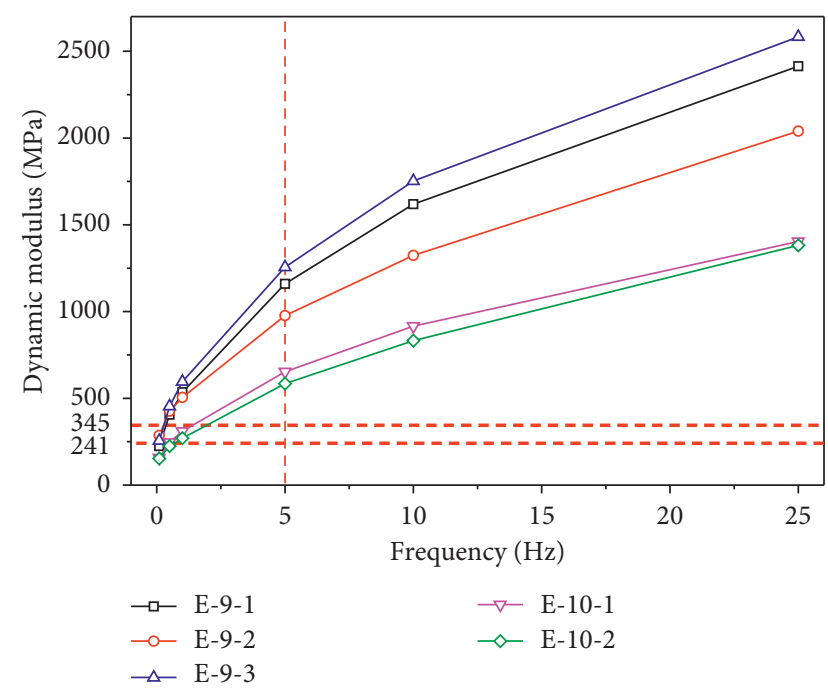

Figure 10: Dynamic modulus at $54.4^{\circ} \mathrm{C}$.

TABle 8: $\left|E^{*}\right|$ values at the low loading frequency under $54.4^{\circ} \mathrm{C}$ (unit: $\mathrm{MPa}$ ).

\begin{tabular}{lcccc}
\hline \multirow{2}{*}{ Test group } & \multicolumn{4}{c}{$54.4^{\circ} \mathrm{C}$} \\
& $0.1 \mathrm{~Hz}$ & $0.5 \mathrm{~Hz}$ & $1 \mathrm{~Hz}$ & $5 \mathrm{~Hz}$ \\
\hline E-9-1 & 225 & 406 & 535 & 1160 \\
E-9-2 & 286 & 426 & 506 & 977 \\
E-9-3 & 256 & 454 & 596 & 1256 \\
E-10-1 & 157 & 247 & 310 & 653 \\
E-10-2 & 153 & 225 & 270 & 585 \\
\hline
\end{tabular}

TABLE 9: Rutting depth of different samples at $65^{\circ} \mathrm{C}$ (TM and MB).

\begin{tabular}{lcc}
\hline Test group & Test condition & $\begin{array}{c}\text { Rutting depth } \\
(\mathrm{mm})\end{array}$ \\
\hline TM-7-1 & & 1.58 \\
TM-7-2 & $65^{\circ} \mathrm{C}$-dry & 1.22 \\
TM-8-1 & & 2.04 \\
TM-8-2 & & 1.47 \\
\hline MB-3-1 & & 2.7 \\
MB-3-2 & $65^{\circ}$ C-dry & 2.19 \\
MB-4-1 & & 3.06 \\
MB-4-2 & & 2.56 \\
\hline
\end{tabular}

whole AC layers, and it could be concluded that the rutting performance of the asphalt pavement was sufficient.

In general, compared with the HWTT, the rutting performance of the full-thickness AC layers could be tested by the dynamic modulus test more directly. Besides, only the dynamic modulus at $54.4^{\circ} \mathrm{C}, 5 \mathrm{~Hz}$ or $54.4^{\circ} \mathrm{C}, 1 \mathrm{~Hz}$ was required when evaluating the rutting performance, which was more time-saving and energy-saving for less cutting.

\section{Conclusions and Recommendations}

A total of 40 field cores were obtained from the Chongqing area and were divided into 10 groups to investigate the rutting performance of field specimens by the HWTT and dynamic modulus test. The main findings are summarized as follows:

(i) Rutting depth of each AC layer is different under different test conditions. 10000 loading cycles are recommended as the maximum loading cycle.

(ii) For the Chongqing area, $55^{\circ} \mathrm{C}$ in the water condition and $65^{\circ} \mathrm{C}$ in the dry condition are recommended as the test condition of the HWTT for the top AC layer. When the top AC layer is the dense graded asphalt mixture, $60^{\circ} \mathrm{C}$ in the dry condition is recommended as the test condition of the HWTT for the middle and bottom AC layers. When the top AC layer is permeable, $50^{\circ} \mathrm{C}$ in the water condition and $60^{\circ} \mathrm{C}$ in the dry condition are proposed as the test condition of the HWTT for the middle and bottom AC layers.

(iii) Test condition and mixture type are two of the major factors influencing HWTT results. Additionally, the influence of the compaction degree on rutting performance could be ignored when it meets the specification requirement. Compared to $4 \mathrm{~cm}$, $6 \mathrm{~cm}$ is a more appropriate specimen height for the HWTT.

(iv) The bottom AC layer contributes the most rutting depth, followed by the middle AC layer and top AC layer.

(v) The dynamic modulus at both $54.4^{\circ} \mathrm{C}, 5 \mathrm{~Hz}$ and $54.4^{\circ} \mathrm{C}, 1 \mathrm{~Hz}$ could effectively represent the rutting performance of the asphalt mixture when the dynamic modulus threshold is $241 \mathrm{MPa}$.

(vi) Compared with the HWTT, the dynamic modulus test is a more convenient test method for the rutting evaluation of the full-thickness AC layers.

It should be noted that there are still some issues that are worth to be discussed. These findings only pertain to the materials and pavement structures investigated in this study. The material and pavement structure are obtained from only one highway, and different materials and pavement structures need to be further addressed.

\section{Data Availability}

Previously reported data (pictures or tables) used to support this study are included within the article. The prior studies (and datasets) are cited at relevant places within the text as reference [46].

\section{Conflicts of Interest}

The authors declare no conflicts of interest regarding the publication of this paper.

\section{Acknowledgments}

This study was funded by the National Nature Science Foundation of China (No. 51878168) and Open Research 
Fund of National Engineering Laboratory for Advanced Road Materials (No. NLARM-ORF-2018-01).

\section{References}

[1] Q. Zhang, Y. Chen, and X. Li, "Rutting in asphalt pavement under heavy load and high temperature," in Proceedings of the Asphalt Material Characterization, Accelerated Testing, and Highway Management: Selected Papers from the 2009 Geo Hunan International Conference, pp. 39-48, Changsha, China, August 2009.

[2] J. Li, G. Liu, T. Yang, J. Zhou, and Y. Zhao, "Research on relationships among different distress types of asphalt pavements with semi-rigid bases in China using association rule mining: a statistical point of view," Advances in Civil Engineering, vol. 2019, Article ID 5369532, 15 pages, 2019.

[3] M. S. Rahman, J. H. Podolsky, and T. Scholz, "Preliminary local calibration of performance prediction models in AASHTOW are pavement ME design for flexible pavement rehabilitation in Oregon," Journal of Transportation Engineering, Part B: Pavements, vol. 145, no. 2, Article ID 05019002, 2019.

[4] R. Eghbalpoor, M. Baghani, and H. Shahsavari, "An implicit finite element framework considering damage and healing effects with application to cyclic moving load on asphalt pavement," Applied Mathematical Modelling, vol. 70, pp. 139-151, 2019.

[5] R. Behnke, I. Wollny, F. Hartung, and M. Kaliske, "Thermomechanical finite element prediction of the structural longterm response of asphalt pavements subjected to periodic traffic load: tire-pavement interaction and rutting," Computers \& Structures, vol. 218, pp. 9-31, 2019.

[6] JTG E20-2011, Standard Test Methods of Bitumen and Bitumen Mixtures for Highway Engineering, People Transportation Press, Beijing, China, 2011, in Chinese.

[7] F. Morea and R. Zerbino, "Wheel tracking test (WTT) conducted under different standards. Study and correlation of test parameters and limits," Materials and Structures, vol. 48, no. 12, pp. 4019-4028, 2015.

[8] H. Wang, Z. Fan, and J. Zhang, "Development of a full-depth wheel tracking test for asphalt pavement structure: methods and performance evaluation," Advances in Materials Science and Engineering, vol. 2016, no. 1, Article ID 1737013, 7 pages, 2016.

[9] H. K. Shanbara, F. Ruddock, and W. Atherton, "Predicting the rutting behaviour of natural fibre-reinforced cold mix asphalt using the finite element method," Construction and Building Materials, vol. 167, pp. 907-917, 2018.

[10] H. K. Shanbara, F. Ruddock, and W. Atherton, "A viscoplastic model for permanent deformation prediction of reinforced cold mix asphalt," Construction and Building Materials, vol. 186, pp. 287-302, 2018.

[11] Q. Li, H. Yang, F. Ni, X. Ma, and L. Luo, "Cause analysis on permanent deformation for asphalt pavements using field cores," Construction and Building Materials, vol. 100, pp. 40-51, 2015.

[12] A. Loaiza and H. A. Colorado, "Marshall stability and flow tests for asphalt concrete containing electric arc furnace dust waste with high $\mathrm{ZnO}$ contents from the steel making process," Construction and Building Materials, vol. 166, pp. 769-778, 2018.

[13] Q. Lv, W. Huang, H. Sadek, F. Xiao, and C. Yan, "Investigation of the rutting performance of various modified asphalt mixtures using the Hamburg wheel-tracking device test and multiple stress creep recovery test," Construction and Building Materials, vol. 206, pp. 62-70, 2019.

[14] M. W. Witczak, NCHRP Report 580: Specification Criteria for Simple Performance Tests for Rutting-Vol. I: Dynamic Modulus ( $\left.E^{*}\right)$ and Vol. II: Flow Number and Flow Time, Transportation Research Board, Washington, DC, USA, 2007.

[15] M. W. Witczak, NCHRP Report 547: Simple Performance Tests: Summary of Recommended Methods and Database, Transportation Research Board, Washington, DC, USA, 2005.

[16] J. Zhang, A. E. Alvarez, S. I. Lee, A. Torres, and L. F. Walubita, "Comparison of flow number, dynamic modulus, and repeated load tests for evaluation of HMA permanent deformation," Construction and Building Materials, vol. 44, pp. 391-398, 2013.

[17] M. W. Witczak, K. Kaloush, T. Pelleinen, and M. El-Basyouny, NCHRP Report 465: Simple Performance Test for Superpave Mix Design, Transportation Research Board, Washington, DC, USA, 2002.

[18] L. F. Walubita, J. Zhang, G. Das et al., "Hot-mix asphalt permanent deformation evaluated by hamburg wheel tracking, dynamic modulus, and repeated load tests," Transportation Research Record: Journal of the Transportation Research Board, vol. 2296, no. 1, pp. 46-56, 2012.

[19] S. W. Goh, Z. You, R. C. Williams, and X. Li, "Preliminary dynamic modulus criteria of HMA for field rutting of asphalt pavements: Michigan's experience," Journal of Transportation Engineering, vol. 137, no. 1, pp. 37-45, 2011.

[20] A. K. Apeagyei, "Rutting as a function of dynamic modulus and gradation," Journal of Materials in Civil Engineering, vol. 23, no. 9, pp. 1302-1310, 2011.

[21] L. F. Walubita, L. Fuentes, S. I. Lee, I. Dawd, and E. Mahmoud, "Comparative evaluation of five HMA rutting-related laboratory test methods relative to field performance data: DM, FN, RLPD, SPST, and HWTT," Construction and Building Materials, vol. 215, pp. 737-753, 2019.

[22] Y. Zhang, T. Ma, X. Ding, T. Chen, X. Huang, and G. Xu, "Impacts of air-void structures on the rutting tests of asphalt concrete based on discretized emulation," Construction and Building Materials, vol. 166, pp. 334-344, 2018.

[23] Y. Zhang, X. Luo, I. Onifade, X. Huang, R. L. Lytton, and B. Birgisson, "Mechanical evaluation of aggregate gradation to characterize load carrying capacity and rutting resistance of asphalt mixtures," Construction and Building Materials, vol. 205, pp. 499-510, 2019.

[24] B. V. Kök, M. Yilmaz, and T. Alataş, "Evaluation of the mechanical properties of field-and laboratory-compacted hotmix asphalt," Journal of Materials in Civil Engineering, vol. 26, no. 9, Article ID 04014064, 2013.

[25] R. Wu, L. Shi, H. Yu et al., "Total thickness rutting research on key influencing factors of asphalt pavement," Journal of Wuhan University of Technology, vol. 30, no. 1, pp. 58-61, 2008, in Chinese.

[26] Q. Lu and J. T. Harvey, "Evaluation of Hamburg wheeltracking device test with laboratory and field performance data," Transportation Research Record: Journal of the Transportation Research Board, vol. 1970, no. 1, pp. 25-44, 2006.

[27] A. Francois, A. Ali, and Y. Mehta, "Evaluating the impact of different types of stabilised bases on the overall performance of flexible pavements," International Journal of Pavement Engineering, vol. 20, no. 8, pp. 938-946, 2019.

[28] J. Ekblad and R. Lundström, "Causes of rutting in flexible and semi-rigid test sections after 14 years of service," Road Materials and Pavement Design, vol. 19, no. 4, pp. 878-897, 2018. 
[29] Y. Zhu, F. Ni, and H. Li, "Calibration and sensitivity analysis of rut prediction model for semi-rigid pavement using AASHTOW are ME design," Road Materials and Pavement Design, vol. 18, pp. 23-32, 2017.

[30] I. Sel, Y. Yildirim, and H. B. Ozhan, "Effect of test temperature on Hamburg wheel-tracking device testing," Journal of $\mathrm{Ma}$ terials in Civil Engineering, vol. 26, no. 8, Article ID 04014037, 2014.

[31] Y. Li, L. Liu, F. Xiao, and L. Sun, "Effective temperature for predicting permanent deformation of asphalt pavement," Construction and Building Materials, vol. 156, pp. 871-879, 2017.

[32] M. J. C. Minhoto, J. C. Pais, P. A. A. Pereira, and L. G. PicadoSantos, "Predicting asphalt pavement temperature with a three-dimensional finite element method," Transportation Research Record: Journal of the Transportation Research Board, vol. 1919, no. 1, pp. 96-110, 2005.

[33] E. O. Lukanen, R. Stubstad, and R. C. Briggs, "Temperature predictions and adjustment factors for asphalt pavement," Turner-Fairbank Highway Research Center, McLean, VA, USA, No. FHWA-RD-98-085, 2000.

[34] J. Qin and L. Sun, "Study on asphalt pavement temperature field distribution pattern," Journal of Highway and Transportation Research And Development, vol. 8, pp. 18-21, 2006, in Chinese.

[35] M. Zheng, L. Han, C. Wang, Z. Xu, H. Li, and Q. Ma, "Simulation of permanent deformation in high-modulus asphalt pavement with sloped and horizontally curved alignment," Applied Sciences, vol. 7, no. 4, p. 331, 2017.

[36] M. Hu, J. Zhang, and X. Huang, "Analysis of rutting characteristics of semi-rigid base asphalt pavement," Journal of Highway And Transportation Research and Development, vol. 28 , no. 6 , pp. 15-18, 2011, in Chinese.

[37] X. Hu, S. Zhong, and L. F. Walubita, "Three-dimensional modelling of multilayered asphalt concrete pavement structures: strain responses and permanent deformation," Road Materials and Pavement Design, vol. 16, no. 3, pp. 727-740, 2015.

[38] JTG F40-2004, Technical Specification for Construction of Highway Asphalt Pavement, People Transportation Press, Beijing, China, 2004, in Chinese.

[39] AASHTO T. 324, Hamburg Wheel-Track Testing of Compacted Hot Mix Asphalt (HMA), Washington DC, USA, 2014.

[40] L. F. Walubita, T. P. Nyamuhokya, B. Naik, I. Holleran, and S. Dessouky, "Sensitivity analysis and validation of the simple punching shear test (SPST) for screening HMA mixes," Construction and Building Materials, vol. 169, pp. 205-214, 2018.

[41] A. H. Gerald, Weather Database for the Superpavetm Mix Design System: Strategic Highway Research Program, SHRP-A648A, National Research Council, Washington DC, USA, 1994.

[42] J. Shen, Road Performance of Asphalt and Asphalt Mixture, People's Communications Press, Beijing, China, 2001, in Chinese.

[43] AASHTO TP 62-03, Standard Method of Test for Determining Dynamic Modulus of Hot-Mix Asphalt Concrete Mixtures, AASHTO, Washington DC, USA, 2001.

[44] AASHTO R 62-13, Developing Dynamic Modulus Master Curves for Asphalt Mixtures, AASHTO, Washington DC, USA, 2013.

[45] T. K. Pellinen and S. Xiao, "Stiffness of hot mix asphalt," Report FHWA/IN/JTRP-2005/20, Purdue University, West Lafayette, IN, USA, 2006.
[46] http://data.cma.cn/site/index.html. 